\title{
The efficacy of repeated needling for calcific tendinitis of the rotator cuff
}

\author{
Hyun Seok Song \\ Department of Orthopedic Surgery, Eunpyeong St. Mary's Hospital, College of Medicine, The Catholic University of Korea, Seoul, Korea
}

Treatment calcific tendinitis of the shoulder remains controversial, with continued debate on whether ultrasound-guided needling and/or lavage, subacromial corticosteroid injection, radial or focused extracorporeal shockwave therapy (ESWT) [1], or arthroscopic removal [2,3] provides optimal outcomes. A prospective randomized trial in 25 patients compared the effectiveness of ultrasound-guided needling and radial shockwave therapy [4]. Ultrasound needling resulted in less pain and faster resorption of calcifications after 6 weeks. However, no significant differences were found after 1 year. A systematic review compared ESWT, ultrasound-guided percutaneous lavage, subacromial corticosteroid injection, and combined treatments for of calcific tendinitis of the shoulder [5]. This meta-analysis suggested that combined ultrasound-guided needling and subacromial corticosteroid injection significantly decreased shoulder pain visual analog scale, improved Constant-Murley score and decreased the size of calcium deposits. Another systematic review concluded that high-energy focused ESWT was the best therapy in terms of functional recovery [6].

There is little evidence regarding the prognostic factors of each modality. Chou et al. [1] reported that a poor prognosis of ESWT for calcific tendinitis was significantly related to Gartner type I calcification, calcification extent $>15 \mathrm{~mm}$ and a duration of symptoms $>11$ months.

Kim et al. [7] reported the clinical outcomes of single (84 cases) and multiple (14 cases) ultrasound-guided injection for calcific tendinitis. All functional scores were significantly improved at the final visit. The group with repeated ultrasound-guided needle decompression of calcific deposits showed worse pain and subjective satisfaction compared to the group that received a single ultrasound-guided needle decompression. At 2 months after the initial needling and injection, ultrasound-guided needling was repeated up to three times if the patient had persistent symptoms and calcific deposits on plain radiography. However, the authors could not determine which poor prognostic factors were associated with repeated needling and injection. These repeated lavage and injections could not be appropriate for these poor prognostic cases. What would the outcome have been at final follow-up if repeated injections had not been undertaken 2 months after the initial injection?

Ultrasound-guided lavage and corticosteroid injection can relieve symptoms and have a role in decreasing calcific deposits. However, multiple needling of the calcific tendinitis can also cause complications. Complications of needling of calcific deposits include injury or tear of the tendon and infection. There are no strict indications for repeated injection. Repeating lavage and

Received: April 24, 2021

Accepted: May 11, 2021

Correspondence to: Hyun Seok Song

Department of Orthopedic Surgery, Eunpyeong St. Mary's Hospital, College of Medicine, The Catholic University of Korea, 1021 Tongil-ro, Eunpyeonggu, Seoul 03312, Korea

Tel: +82-2-2030-4628, Fax: +82-2-2030-4629, E-mail: hssongmd@ @anmail.net, ORCID: https://orcid.org/0000-0002-7844-2293

Financial support: None.

Conflict of interest: None.

Copyright@ 2021 Korean Shoulder and Elbow Society.

This is an Open Access article distributed under the terms of the Creative Commons Attribution Non-Commercial License (http://creativecommons.org/licenses/by-nc/4.0/) which permits unrestricted non-commercial use, distribution, and reproduction in any medium, provided the original work is properly cited. 
corticosteroid injections until the calcific deposits resolve completely is not recommended. Because of the lack of evidence regarding the efficacy, the risks and benefits of repeated needling (lavage) and injection should be carefully considered.

\section{ORCID}

Hyun Seok Song

https://orcid.org/0000-0002-7844-2293

\section{REFERENCES}

1. Chou WY, Wang CJ, Wu KT, Yang YJ, Ko JY, Siu KK. Prognostic factors for the outcome of extracorporeal shockwave therapy for calcific tendinitis of the shoulder. Bone Joint J 2017;99:164350.

2. Franceschi F, Longo UG, Ruzzini L, Rizzello G, Denaro V. Arthroscopic management of calcific tendinitis of the subscapularis tendon. Knee Surg Sports Traumatol Arthrosc 2007;15:1482-5.

3. Hashiguchi H, Iwashita S, Okubo A, Takai S. Arthroscopic removal and tendon repair for refractory rotator cuff calcific ten- dinitis of the shoulder. J Nippon Med Sch 2017;84:19-24.

4. De Boer FA, Mocking F, Nelissen EM, Van Kampen PM, Huijsmans PE. Ultrasound guided needling vs radial shockwave therapy in calcific tendinitis of the shoulder: a prospective randomized trial. J Orthop 2017;14:466-9.

5. Arirachakaran A, Boonard M, Yamaphai S, Prommahachai A, Kesprayura S, Kongtharvonskul J. Extracorporeal shock wave therapy, ultrasound-guided percutaneous lavage, corticosteroid injection and combined treatment for the treatment of rotator cuff calcific tendinopathy: a network meta-analysis of RCTs. Eur J Orthop Surg Traumatol 2017;27:381-90.

6. Wu YC, Tsai WC, Tu YK, Yu TY. Comparative effectiveness of nonoperative treatments for chronic calcific tendinitis of the shoulder: a systematic review and network meta-analysis of randomized controlled trials. Arch Phys Med Rehabil 2017;98: 1678-92.e6.

7. Kim SC, Lee SM, Park GT, Jang MC, Yoo JC. Ultrasound-guided needle decompression and steroid injection for calcific tendinitis of the shoulder: risk factors for repeat procedures and outcome analysis. Clin Shoulder Elbow 2021;24:55-65. 